\title{
R-S recall as a function of opportunity for intratrial rehearsal'
}

KEITH A. WOLLEN AND GORDON G. GALLUP, JR. WASHINGTON STATE UNIVERSITY

\begin{abstract}
The hypothesis was advanced that at least a portion of $\mathrm{R}-\mathrm{S}$ learning is attributable to successive repetitions of the members of paired-associate lists. Opportunity for such intratrial rehearsal was manipulated by varying the presentation rate of noun-noun pairs. Although all Ss were taken to the same S-R criterion, the group with a 4-sec. rate evidenced more R-S learning than Ss with a 1-sec. rate. The data were interpreted as consistent with the intratrial rehearsal hypothesis.

\section{Problem}

It is well known that Ss instructed to learn paired associates in the forward (S-R) direction are also able to recall them in the backward (R-S) direction. However, as Underwood \& Keppel (1963) pointed out, "Why any backward learning occurs is still not known, and why it is less than forward learning is also not known ..." The purpose of the present experiment was to examine one interpretation of backward associations.

Specifically, the hypothesis is advanced that backward associations result partially or entirely from intratrial rehearsal (ITR) in which S covertly or overtly repeats the members of a pair several times in succession, e. g. S-R-S-R-S-R. If such rehearsal were to occur, $S$ would follow as well as preceed $R$ thereby resulting in specific rehearsal in the $\mathrm{R}-\mathrm{S}$ direction. Since the typical presentation rate is relatively slow $(2 \mathrm{sec}$. for $S$ and $2 \mathrm{sec}$. for $S$ and $R$ ), ITR would generally be possible and may account for R-S associations.

One test of the ITR hypothesis would be to vary the rate of presentation. Presumably, Ss with less time to rehearse would show less $\mathrm{R}-\mathrm{S}$ recall. Such was found to be the case in a study by Cassem \& Kausler (1962) who gave Ss with different rates the same number of S-R trials thereby permitting rate and amount of S-R learning to covary. Jantz \& Underwood (1958) have demonstrated that $R-S$ recall increases with increases in the amount of S-R learning. Consequently, the greater $\mathrm{R}-\mathrm{S}$ recall for the slow rate might not have resulted from rate per se but from the fact that these Ss had more S-R learning. In the present experiment, Ss were taken to the same S-R criterion in an attempt to eliminate differences in S-R learning and thus permit a better test of the effect of rate.

\section{Method}

The Ss, 15 females and 13 males, were given alternating study and test trials using a Lafayette drum to present the following list of noun-noun pairs: wallbutter, gate-letter, office-road, salt-nation, door-music, flower-iron, valley-king, people-tree. For one group of $14 \mathrm{Ss}$, the $\mathrm{S}$ member appeared for $1 \mathrm{sec}$. in the left side of the window and was followed by the $\mathbf{R}$ member for $1 \mathrm{sec}$. in the right side. The $S$ and $R$ members were never presented simultaneously. For the other group of $14 \mathrm{Ss}$, each member was presented for $4 \mathrm{sec}$. The Ss were instructed to pronounce each word aloud as soon as it appeared. On test trials, only the $\mathrm{S}$ items were presented. A 2-sec. rate was used for both groups, and $S$ was instructed to pronounce the appropriate $\mathbf{R}$ without articulating the $\mathrm{S}$.

All Ss were taken to a criterion of four out of eight correct on a single test trial. Then all Ss were given three $\mathrm{R}-\mathrm{S}$ recall trials in succession at a $2-\mathrm{sec}$. rate. Three different list orders were used on study trials, a different three orders on test trials, and three additional orders on $\mathrm{R}-\mathrm{S}$ recall trials. All interlist intervals were $2 \mathrm{sec}$.

\section{Results and Diseussion}

The right-hand portion of Fig. 1 shows the mean number correct over all three recall trials. As predicted, there was significantly more $R-S$ recall in the 4-sec. group $(t=3.73, d f=26, p<.001)$. In order to interpret this finding as support for the ITR hypothesis, it is necessary to show that the differences in $\mathrm{R}-\mathrm{S}$ recall are attributable to rate and not to differences in the amount of S-R learning. In order to do this, the mean number correct on the S-R criterion trial was examined. These data, which are presented in the left-hand portion of Fig. 1, reveal a slight tendency for Ss with the slow rate to surpass the criterion more than Ss with the fast rate. Although this difference was not statistically significant $(t=1.89, \mathrm{df}=26)$, it seems likely that more power would have resulted in significance since slow

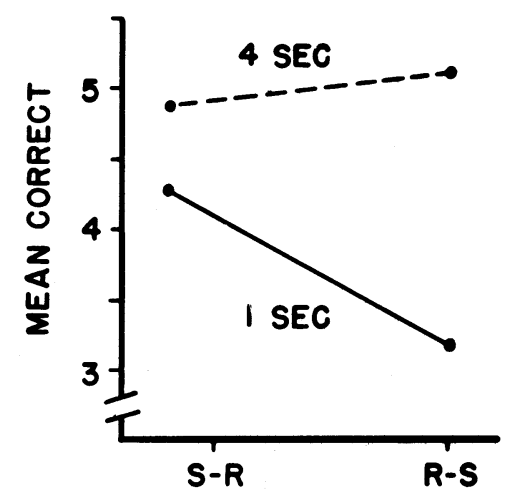

Fig. 1. Mean number correct on the $S-R$ criterion trial and $R-S$ recall as a function of presentation rate. 
rates produce more learning per trial. Thus part of the superiority of the slow group might be due to greater S-R learning.

A post hoc: check of this possibility was made by eliminating the data of Ss who exceeded the S-R criterion by two or more items. This procedure, which amounted to discarding three Ss with 6 correctand one with 7 from the 4-sec. condition, eliminated the differences between the 1 and 4-sec. groups. However, the difference between the groups in $\mathrm{R}-\mathrm{S}$ recall was relatively unaffected (1.7 as opposed to 1.9). As a still further check, the difference in $\mathrm{R}-\mathrm{S}$ recall was significant when the effects of S-R learning were removed via an analysis of covariance $(F=13.04, \mathrm{df}=1 / 25, \mathrm{p}<.001)$.

Before the recall data can be interpreted as support for the ITR notion, it is also necessary to demonstrate that there was more opportunity for ITR in the 4-sec. condition. Ss in the 1-sec. group may have compensated for less ITR per trial by taking more trials to reach criterion. If this were the case, opportunity for ITR might be approximately equal for the two groups. However, each $\mathrm{S}$ and $\mathrm{R}$ member in the 4-sec. group was exposed, on the average, for a total of $6.28 \mathrm{sec}$. as opposed to $4.64 \mathrm{sec}$. in the $1-\mathrm{sec}$. condition. Furthermore, the 1-sec. mean would have been 3.84 except for one $\mathrm{S}$ who took 15 trials to criterion. Thus, since more time was available for rehearsal in the 4-sec. group, the data are consistent with the ITR hypothesis.

The R-S recall data appear contradictory to the associative symmetry hypothesis advanced by Asch \& Ebenholtz (1962) that R-S and S-R associations are equal in strength. From this notion, it would seem to follow that groups learning the same materials and equated on S-R learning would also be equated with respect to the amount of $\mathrm{R}-\mathrm{S}$ recall. However, this was not the case since the 4-sec. group recalled more in the R-S test.

A more direct test of associative symmetry would be to compare the number correct in $\mathrm{R}-\mathrm{S}$ recall with the number correct on the $S-R$ criterion trial. As would be expected, these values are approximately equal for the 4-sec. condition (see Fig. 1). However, in the 1-sec. group, there were fewer correct on the R-S test than on the S-R criterion trial. This suggests that associative symmetry is a function of opportunity for ITR.
According to Asch and Ebenholtz, failure to obtain symmetry is due to lower availability of S members, which results from the fact that $S$ does not have to produce the $S$ whereas he does have to produce the $R$. It may be that slow rates permit more ITR with the result that $S$ produces both $S$ and $R$ members. Such rehearsal would tend to equate the availability of $S$ and $\mathbf{R}$ members, and would, therefore, increase the likelihood of finding symmetry. Thus the possibility exists that ITR underlies associative symmetry, at least in part.

The associative symmetry hypothesis must be held suspect even for the 4-sec. group. The symmetry notion would seem to imply that not only would the total number of S-R and R-S associations be equal, but that the same associations would be present in either direction. In the 4-sec. condition, $27 \%$ of the R-Sassociations on the first recall trial had never been correct in the S-R direction. Thus, even though associative symmetry occurred for the grouped data, asymmetry was evidenced for individual associations. Moreover, this asymmetry was not restricted to the $4-\mathrm{sec}$. group since $16 \%$ of the R-S associations in the $1-\mathrm{sec}$. condition were likewise never correct in the $S-R$ phase.

The occurrence of asymmetry would pose no problem for the ITR hypothesis since, as Richardson (1960) has emphasized, associations may be easier to form in one direction than in another. Thus it is quite reasonable that associations may be stronger in the R-S direction. Further tests of this possibility are underway.

\section{Referenees}

Asch, S. E., \& Ebenholtz, S. M. The principle of associative symmetry. Proc. Amer. Phil. Soc., 1962, 106, 135-163.

Cassem, N. \& Kausler, D. H. Supplementary report: Effects of stimulus association value and exposure duration on R-S learning. J. exp. Psychol., 1962, 64, 94.

Jantz, E. M., \& Underwood, B. J. R-S learning as a function of meaningfulness and degree of S-R learning. J. exp. Psychol., 1958, 56, 174-179.

Richardson, J. Comparison of S-R and R-S learning of paired-associates. Psychol. Rep., 1960, 7, 225-228.

Underwood, B. J., \& Keppel, G. Bidirectional paired-associate learning. Amer. J. Psychol., 1963, 76, 470-474.

Note

1. This investigation was supported in part by Public Health Service Research Grant MH 11494-01, from the National Institute of Mental Health. 